\title{
Study of particulate matters pollution related with meteorological factors for a city from South-Central of Romania
}

\author{
Gabriela MITRAN ${ }^{1}$, Sorin ILIE ${ }^{1}$
}

\begin{abstract}
:
Reducing the effects of climate change and air pollution is at present a global priority. Development and implementation of effective policies in order to achieve these reductions is a challenge that requires a good understanding of the underlying phenomena of climate change and air pollution. This paper aims to highlight the seasonal variation of $\mathrm{PM}_{10}$ concentration in Pitesti city depending on major meteorological factors (temperature, intensity of solar radiation, and relative humidity). The applied methodology consists in statistical processing, using specialized software, of a database containing historical records of concentration values of this pollutant and of meteorological parameters recorded concurrently. The results of processing a series of approximately 30000 values recorded from 2008 to 2011 indicate the fact that in every season (winter, spring, summer, and autumn) the concentration of $\mathrm{PM}_{10}$ varies according to a sixth degree polynomial function, whose variable is one of the considered meteorological factors. The mathematical relationship that best approximates the variation of average $\mathrm{PM}_{10}$ concentration in relation with the three meteorological factors is by the form of a multiple linear regression equation.
\end{abstract}

Keywords: air pollution and human health, particulate matters related with meteorological factors, statistical analysis

\section{Introduction}

The population and the environment are exposed to various pollutants produced by natural and/or anthropogenic sources, but also from complex chemical reactions that occur in the atmosphere. Many of these substances can cause serious health problems of the population and can have a negative impact on ecosystems. Of these substances, particulate matters (PM) are pollutants that pose the greatest problems concerning human health (Ranzi et al., 2004), (Dimitrova et al., 2012). The exposure of population over a long period in an environment in which they are present PM increases the risk of respiratory and cardiovascular diseases (Donaldson, Gilmour, \& MacNee, 2000). An important problem is represented by the particles with aerodynamic diameter smaller than 10 micrometers $\left(\mathrm{PM}_{10}\right)$, which pass through the nose and throat and enter the pulmonary alveoli, causing inflammation and intoxication. In addition to problems linked to the human health, PM may have detrimental effects on climate and ecosystems 
(Carnevale, Pisoni, \& Volta, 2008). Particulate matters are inhalable particles, harmful to human health and to environment aesthetics, which spread locally and regionally (under the action of atmospheric transport). At the level of European Union Member States, in 2010, the major producing sources of $\mathrm{PM}_{10}$ were the commercial activities and fuel consumption in households (41\%), transports $(17 \%)$ and industrial processes $(15 \%)$ (European Environment Agency, 2012). The concentration of $\mathrm{PM}_{10}$ in the atmosphere is closely correlated with meteorological parameters in the frame of dispersion processes and the atmospheric transport. Further, in this work the authors highlighted the variations in quantity of $\mathrm{PM}_{10}$, both relative to each of the meteorological parameters (temperature, intensity of solar radiation, and relative humidity), and relative to all these parameters, in the same time, corresponding to the urban environment of Pitesti, a medium sized city in Romania. The variation functions in relation to the independent variables above mentioned are determined using numerical programs specialized in analysis and statistical processing of data.

\section{Framework}

The city of Pitesti, the residence of Arges county, is located in the south-central part of Romania, between the Carpathians mountains and the Danube river, at the confluence of Arges and Doamnei rivers, in the intersection point of the parallel of $44^{\circ} 51^{\prime} 30$ north latitude with the meridian of $24^{\circ} 52^{\prime}$ east longitude, at approximately equal distance from the North Pole and the Equator, the parallel of $45^{\circ}$ crossing at a distance of $20 \mathrm{~km}$ from Pitesti. The city is located at altitudes between $252 \mathrm{~m}$ (in the South) and $356 \mathrm{~m}$ (in the North-West). The vicinities of the city rises at levels of $373 \mathrm{~m}$ - in West zone, $406 \mathrm{~m}$ - in East zone and $439 \mathrm{~m}$ - in North-West zone, which means the locality is in a depressionary area. The climate is temperate continental forest type, hilly floor. The city itself, located between the piedmont high hills, on the terraces of Arges river, has a topo-climate of a valley, prevailing calm, moderate weather. In the winter months are not recorded very low temperatures or strong storms and summers are less hot. The multiannual average temperature is $9.7^{\circ} \mathrm{C}$, the absolute maximum temperature is 38.8 ${ }^{\circ} \mathrm{C}$, and the absolute minimum temperature is $-24.4{ }^{\circ} \mathrm{C}$. The total amount of annual precipitations is $663.3 \mathrm{~mm}$. The air circulation is produced mostly from the North-East $(26 \%)$, and then from North (14\%), West $(12 \%)$ and East $(11 \%)$. The atmospheric calm has a frequency of $15 \%$. The average yearly speed is $2.6 \mathrm{~m} / \mathrm{s}$, ranging from $0.9 \mathrm{~m} / \mathrm{s}$ from South-West in December, to $4.7 \mathrm{~m} / \mathrm{s}$ from East in March. The atmospheric humidity is, on average, of $68 \%$.

\section{Methodology}

\subsection{Experimental data}

Starting with 2008 in Romania operates National Network for Air Quality Monitoring, consisting of 41 local centers in which are located 142 stations for continuously monitoring air quality, endowed with automatic equipments for measurement the concentrations of the main air pollutants. These stations are grouped into six categories according to the main pollution factors in their area of influence, as 
following: (1) traffic type stations, (2) industrial type stations, (3) urban background type stations, (4) suburban background type stations, (5) regional background type stations and (6) EMEP (European Monitoring and Evaluation Programme) type stations, for monitoring and evaluation of air pollution in long distance trans-boundary context (Ministry of Environment and Forests, 2012). In the city of Pitesti are operating two air quality monitoring stations: station AG1 (of traffic type, whose representativeness radius is between $10 \mathrm{~m}$ and $100 \mathrm{~m}$; the monitored pollutants are: $\mathrm{NO}, \mathrm{NO}_{2}, \mathrm{NO}_{\mathrm{x}}, \mathrm{SO}_{2}, \mathrm{CO}$, $\mathrm{PM}_{10}, \mathrm{BTEX}, \mathrm{Pb}, \mathrm{Cd}, \mathrm{Ni}, \mathrm{As}$ ) and station AG2 (of urban background type, whose representativeness radius is between $1 \mathrm{~km}$ and $5 \mathrm{~km}$; the monitored pollutants are: $\mathrm{NO}$, $\mathrm{NO}_{2}, \mathrm{NO}_{x}, \mathrm{SO}_{2}, \mathrm{CO}, \mathrm{O}_{3}, \mathrm{PM}_{10}, \mathrm{BTEX}$. Station AG2 is centrally located in the city, within the pedestrian area and, in addition to station AG1, it monitors also the meteorological parameters (direction and speed of wind, pressure, temperature, intensity of solar radiation, relative humidity, the amount of precipitations).

\subsection{Analysis method}

The variation of $\mathrm{PM}_{10}$ amount associated to urban background in Pitesti municipality, generated by stationary producing pollutants sources, as well as by mobile sources, in relation to the meteorological parameters - temperature, intensity of solar radiation, and relative humidity - was studied using logical scheme presented in Figure 1.

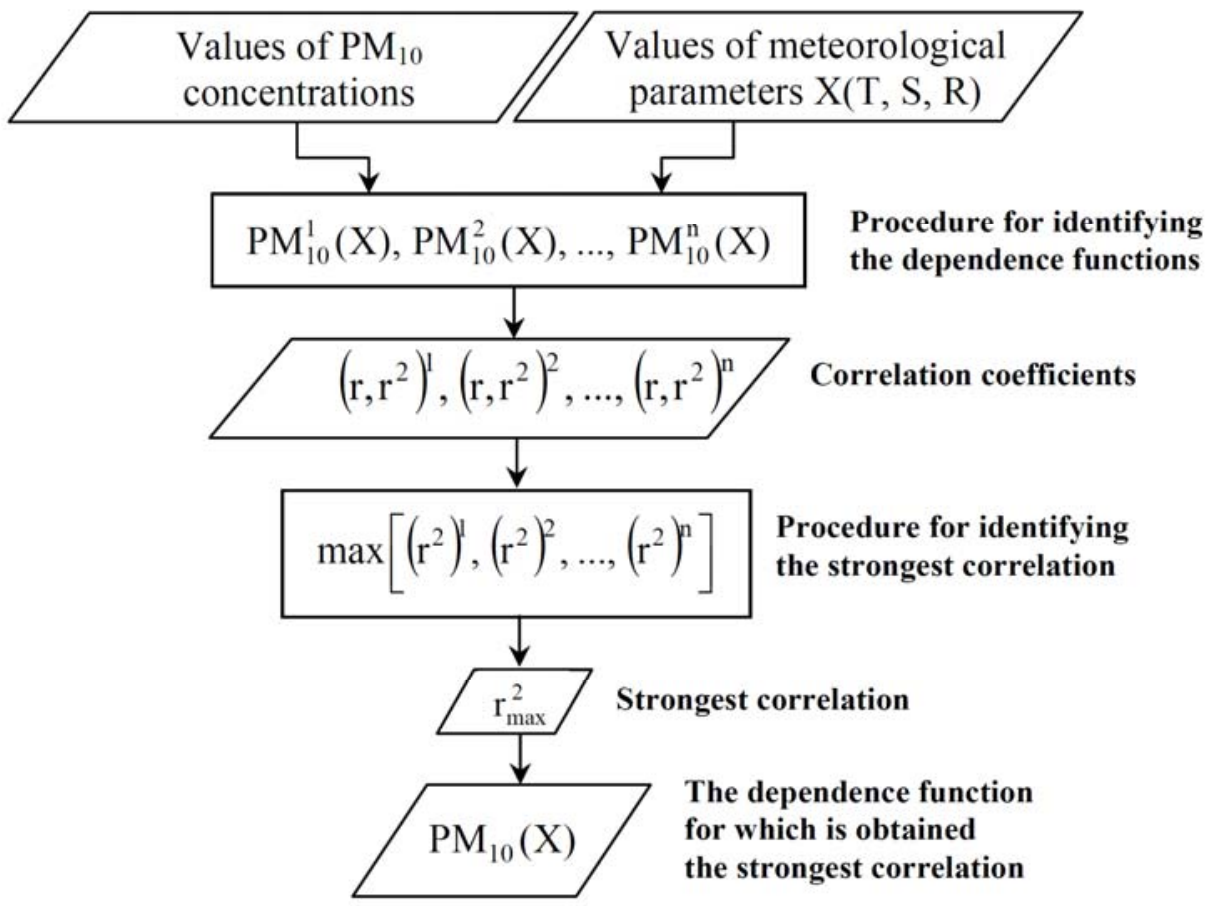

Figure 1. Logical scheme for studying the dependence of $P M_{10}$ on meteorological parameters. 
In this work we used a set of approximately 30000 valid entries for the values of $\mathrm{PM}_{10}$ emission factor and for the following meteorological parameters: temperature, intensity of solar radiation, and relative humidity, recorded at intervals of one hour, in the air quality monitoring station AG2, located in the city centre. For each of the monitored parameters (of pollution and of weather), we computed the hourly average values specific to the four seasons: winter, spring, summer, and autumn. The database that contains the data, from the two monitoring air quality fixed stations, recorded in the period January 2008 to December 2011 were obtained from Regional Environmental Protection Agency Pitesti based on a protocol agreed between this institution and University of Pitesti.

Statistical processing of the four sets of values was performed with TableCurve 2D software, which allows the identification of a set of several hundreds of mathematical variation functions for each relationship examined, indicating both their mathematical expressions and graphical representations in the coordinate system xOy. Also, for each of the identified mathematical functions, it provides the coefficient of determination $\mathrm{r}^{2}$, which helps to identify the best analytical expressions that describe a relationship between two or more parameters whose values were determined empirically.

\section{Results And Discussions}

The variation of average seasonal amount of $\mathrm{PM}_{10}$, in time interval 2008-2011, indicate the fact that in summer are recorded minimum values of this pollutant in atmosphere, whereas in autumn and in winter, this amount increases by up to $50 \%$ compared to values in summer months. The average concentration of this pollutant in the atmosphere varies between $22.2 \mu \mathrm{g} / \mathrm{m}^{3}$ and $41.8 \mu \mathrm{g} / \mathrm{m}^{3}$. According to the legislation in Romania, the limit values are: $50 \mu \mathrm{g} / \mathrm{m}^{3}$ - daily limit value for human health protection; $40 \mu \mathrm{g} / \mathrm{m}^{3}$ - average annual daily limit value for human health protection and $25 \mu \mathrm{g} / \mathrm{m}^{3}$ - average annual daily limit value to be achieved until January, 1 ${ }^{\text {st }}, 2015$ (Parliament of Romania, 2011). The time interval in which there has been recorded the seasonal minimum value for all seasons is 14:00-15:00 a.m., followed by an abrupt increase, which leads to achieving the maximum values in the time range of 21:00-22:00 a.m. (Figure 2).

The seasonal hourly average temperature in the four years of analysis varies according to the curves in Figure 3. In the analysis have been highlighted also the hourly variations of other two meteorological factors influencing the dispersion and transport of $\mathrm{PM}_{10}$ amount discharged into the atmosphere, namely, the intensity of solar radiation, and the relative humidity. The graphical representations of these variations for each season can be found in Figures 4 and 5. 




Figure 2. Seasonal hourly variation of $P M_{10}$.



Figure 3. Seasonal hourly variation of temperature. 


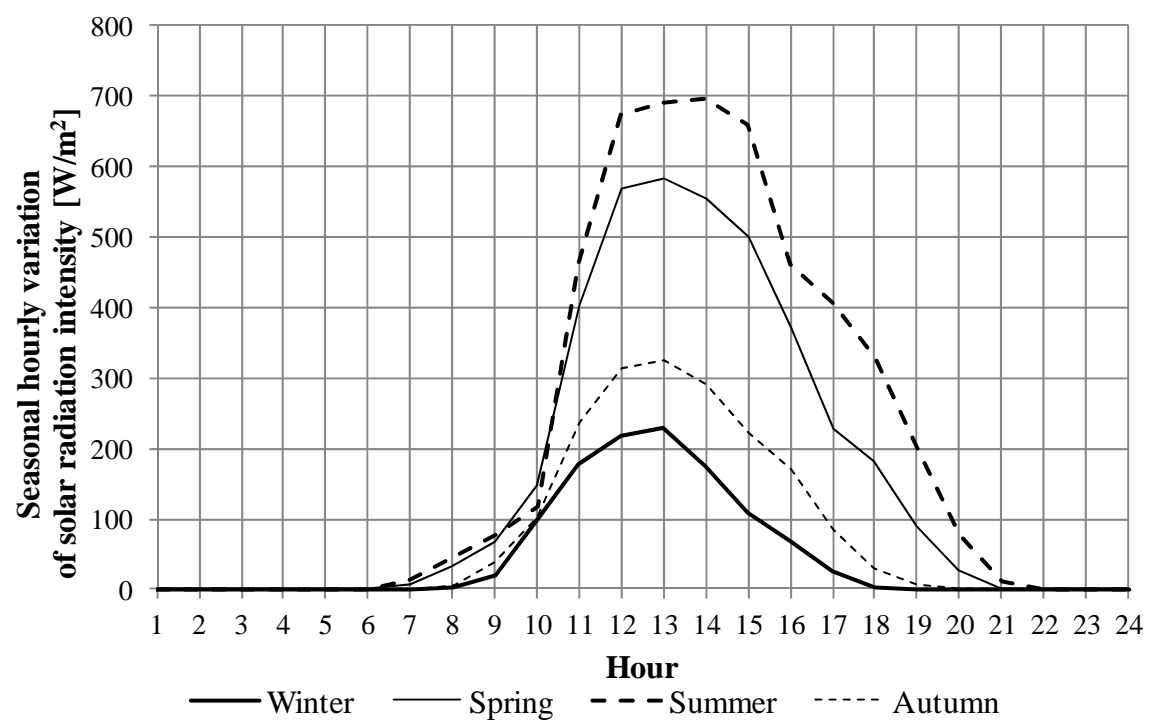

Figure 4. Seasonal hourly variation of solar radiation intensity.

The territory of Pitesti municipality is located along the river Arges, which makes the relative humidity during the night and morning to vary between $70 \%$ and $80 \%$ (Figure 5). We approximated the variations of $\mathrm{PM}_{10}$ concentration in the analyzed area, established in relation to independent variables (temperature, intensity of solar radiation, and relative humidity of air) with the help of TableCurve $2 D$ software by polynomial functions of the type (1):

$P M_{10}=a_{0}+a_{1} \cdot X+a_{2} \cdot X^{2}+a_{3} \cdot X^{3}+a_{4} \cdot X^{4}+a_{5} \cdot X^{5}+a_{6} \cdot X^{6}$

where: $\mathrm{X}$ is independent variable ( temperature $\mathrm{T}$; intensity of solar radiation $\mathrm{S}$ and relative humidity of air $\mathrm{R}$ ), and $\mathrm{a}_{0}, \mathrm{a}_{1}, \mathrm{a}_{2}, \mathrm{a}_{3}, \mathrm{a}_{4}, \mathrm{a}_{5}, \mathrm{a}_{6}$ are coefficients.

The values of variation function coefficients for each independent variable considered, and the values of correlation and determination coefficients ( $\mathrm{r}$ and, respectively, $\mathrm{r}^{2}$ ), are shown in Table 1, corresponding to the four seasons studied. Analyzing data from the Table 1, it can be observed that in all seasons there is a strong correlation between the amounts of $\mathrm{PM}_{10}$ existing in the atmosphere and the considered meteorological parameters (Song, 2007). 


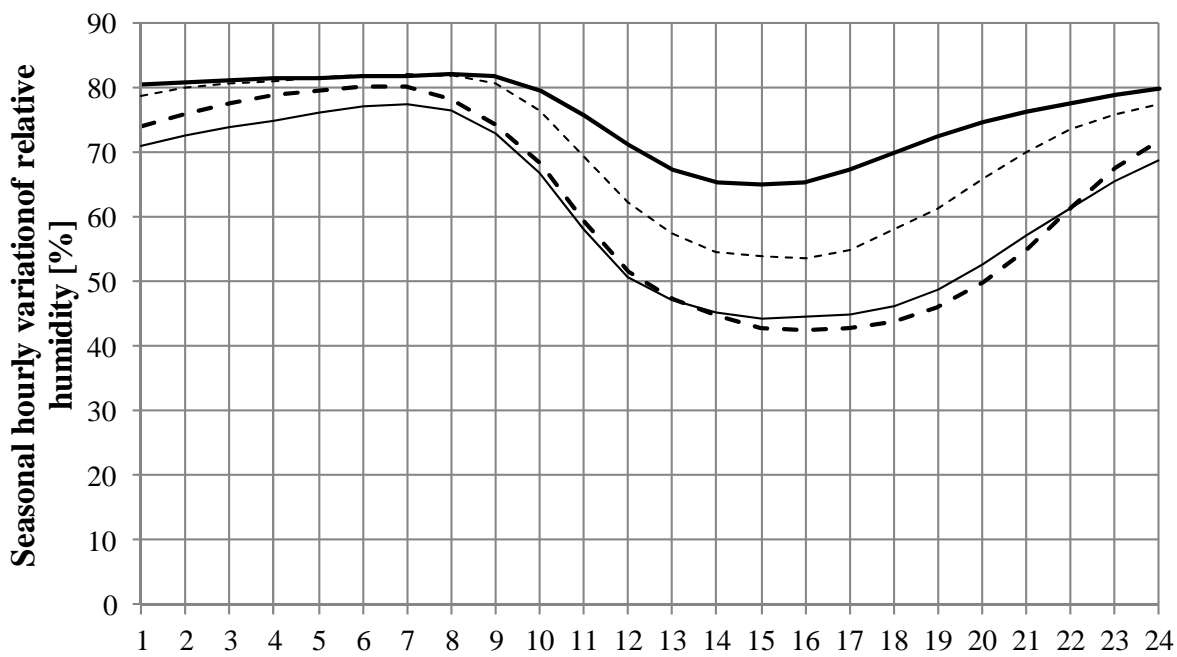

Hour

- Winter $\longrightarrow$ Spring

- - - Summer ---- Autumn

Figure 5. Seasonal hourly variation of relative bumidity.

Table 1. The values of coefficients for $\mathrm{PM}_{10}$ variations functions depending on $\mathrm{T}, \mathrm{S}$, and $\mathrm{R}$ variables. The values of correlation and determination coefficients.

\begin{tabular}{|c|c|c|c|c|c|c|c|c|c|c|}
\hline Season & $\mathbf{X}$ & $a_{0}$ & $a_{1}$ & $a_{2}$ & $a_{3}$ & $a_{4}$ & $a_{5}$ & $a_{6}$ & $\mathbf{r}$ & $\mathbf{r}^{2}$ \\
\hline \multirow{3}{*}{ Winter } & $T$ & 34.661 & 3.993 & 0.5463 & -0.8038 & 0.1237 & 0.0017 & -0.001 & 0.97 & $94 \%$ \\
\hline & $S$ & 33.693 & 0.1324 & -0.01 & 0.0002 & $-2 \mathrm{E}-06$ & $7 \mathrm{E}-09$ & $-1 \mathrm{E}-11$ & 0.81 & $65 \%$ \\
\hline & $R$ & $-5 E+06$ & 423672 & -14641 & 269.55 & -2.7885 & 0.0154 & $-4 \mathrm{E}-05$ & 0.95 & $91 \%$ \\
\hline \multirow{3}{*}{ Spring } & $T$ & 474.96 & -210.94 & 38.078 & -3.2921 & 0.1386 & -0.0023 & 0 & 0.92 & $85 \%$ \\
\hline & $S$ & 38.658 & -0.1651 & 0.0029 & $-2 \mathrm{E}-05$ & $7 \mathrm{E}-08$ & $-1 \mathrm{E}-10$ & 6E-14 & 0.84 & $71 \%$ \\
\hline & $R$ & 9941.3 & -1124.8 & 51.904 & -1.2514 & 0.0167 & -0.0001 & $3 \mathrm{E}-07$ & 0.95 & $90 \%$ \\
\hline \multirow{3}{*}{ Summer } & $T$ & 114861 & -32445 & 3791.4 & -234.58 & 8.1059 & -0.1484 & 0.0011 & 0.94 & $88 \%$ \\
\hline & $S$ & 38.394 & -0.1336 & 0.0019 & $-1 \mathrm{E}-05$ & 2E-08 & $-2 \mathrm{E}-11$ & $1 \mathrm{E}-14$ & 0.77 & $59 \%$ \\
\hline & $R$ & 5186.2 & -573.63 & 25.881 & -0.6083 & 0.0079 & $-5 \mathrm{E}-05$ & $1 \mathrm{E}-07$ & 0.91 & $83 \%$ \\
\hline \multirow{3}{*}{ Autumn } & $T$ & 8013.2 & -4617.1 & 1093.5 & -135.94 & 9.3752 & -0.3406 & 0.0051 & 0.97 & $95 \%$ \\
\hline & $S$ & 36.612 & -0.1879 & 0.0059 & - 7E-05 & $3 \mathrm{E}-07$ & $-6 \mathrm{E}-10$ & $5 \mathrm{E}-13$ & 0.81 & $65 \%$ \\
\hline & R & -16184 & 1626.4 & $\begin{array}{c}- \\
67.898\end{array}$ & 1.5063 & -0.0187 & 0.0001 & $-3 \mathrm{E}-07$ & 0.97 & $94 \%$ \\
\hline
\end{tabular}

In order to estimate the concentrations of $\mathrm{PM}_{10}$ existing in the atmosphere, assuming that the average amounts emitted every season are equal to those of time interval 2008 2010, the authors determined the variation functions of concentrations of this emission 
factor in relation to all three meteorological parameters whose influence has been analyzed previously independently. From the set of functions identified using statistical analysis software, have been validated as expressing more accurately the dependence between these variables, the multiple linear regression functions, of the form (2) (Dusa, 2006):

$$
\mathrm{PM}_{10}=\mathrm{b}_{0}+\mathrm{b}_{1} \cdot \mathrm{T}+\mathrm{b}_{2} \cdot \mathrm{S}+\mathrm{b}_{3} \cdot \mathrm{R}
$$

where: $\mathrm{T}$ is the temperature; $\mathrm{S}$ is the intensity of solar radiation; $\mathrm{R}$ is the relative humidity of air, and $b_{0}, b_{1}, b_{2}, b_{3}$ are regression coefficients.

The values of regression coefficients and the values of correlation and determination coefficients ( $\mathrm{r}$ and, respectively, $\mathrm{r}^{2}$ ), for each season, are shown in Table 2. The results indicate that there is a strong correlation between the set of three independent variables (temperature, intensity of solar radiation, and relative humidity) and the amount of $\mathrm{PM}_{10}$ existing in the atmosphere for winter and spring months, and a moderate correlation for the months in summer and autumn (Song, 2007).

Table 2. The regression coefficients of $\mathrm{PM}_{10}$ functions.

The values of correlation and determination coefficients

\begin{tabular}{|c|c|c|c|c|c|c|c|}
\hline Season & $\mathbf{b}_{\mathbf{0}}$ & $\mathbf{b}_{\mathbf{1}}$ & $\mathbf{b}_{\mathbf{2}}$ & $\mathbf{b}_{\mathbf{3}}$ & $\mathbf{a}_{\mathbf{4}}$ & $\mathbf{r}$ & $\mathbf{r}^{\mathbf{2}}$ \\
\hline Winter & -172.984 & .100 & .007 & .546 & .98 & $6 \%$ & -172.984 \\
\hline Spring & -206.538 & .643 & .006 & .219 & .94 & $9 \%$ & -206.538 \\
\hline Summer & -99.550 & .325 & 0.004 & .843 & .79 & $3 \%$ & -99.550 \\
\hline Autumn & -37.857 & .756 & 0.017 & .634 & .6 & $6 \%$ & -37.857 \\
\hline
\end{tabular}

The graphical representations of measured quantitative variations of $\mathrm{PM}_{10}$ in the atmosphere and those calculated using multiple linear regression relations whose coefficients were given in Table 2, are shown in Figures 6, a - d.

\section{Conclusions}

In this paper the authors highlighted the seasonal variations of the amounts of particulate matter with diameter less than 10 micrometers, as well as the variations of the main meteorological factors specific to the city of Pitesti, based on a data set recorded at each hour in the time period January 2008 - December 2011. 
a)



- - -PM10_measured — PM10_regression

b)

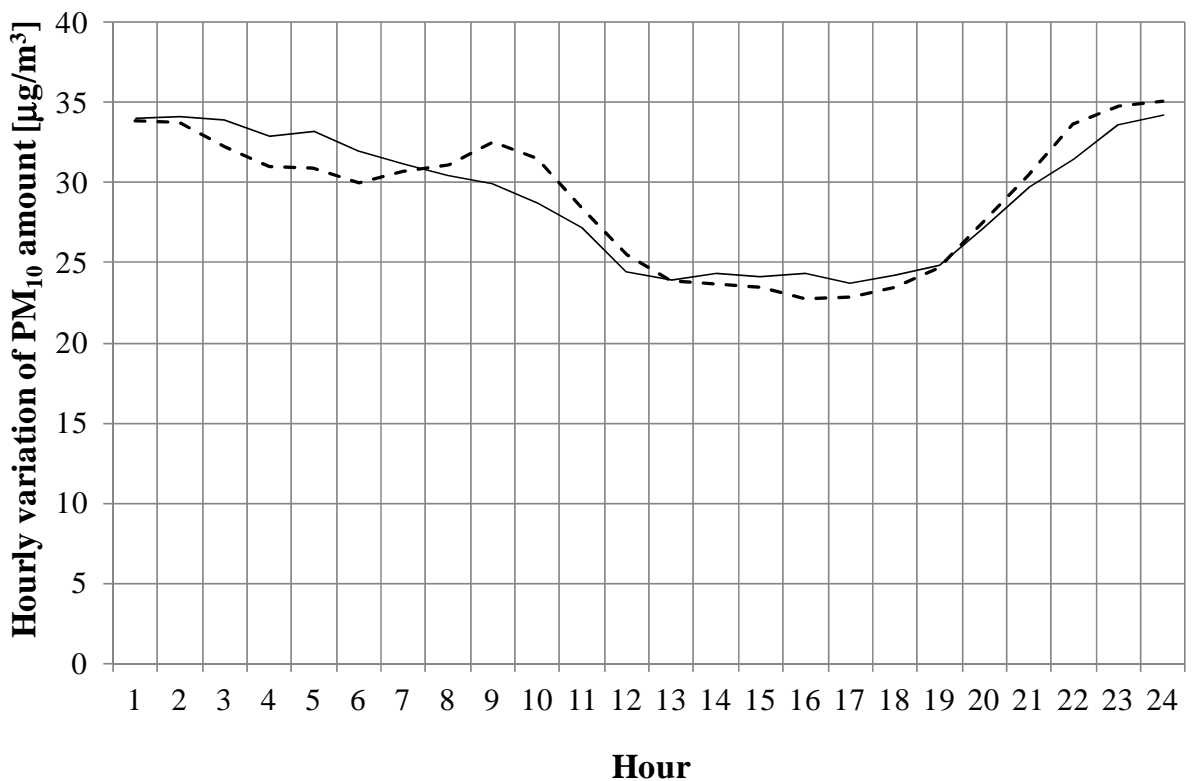

---PM10_measured —-PM10_regression 
c)



- - -PM10_measured — PM10_regression

d)

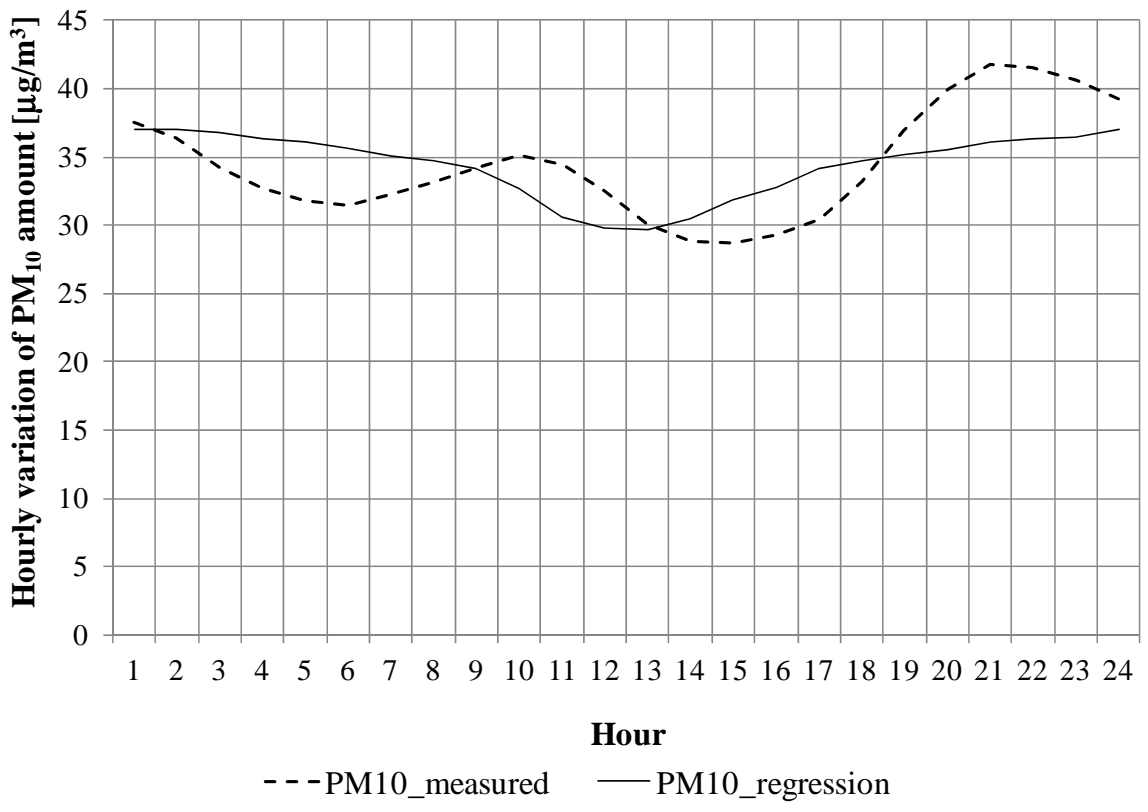

Figure 6. Measured and calculated hourly variations of $\mathrm{PM}_{10}$.

a) Winter; b) Spring; c) Summer; d) Autumn.

Following processing and statistical analysis of recorded data, we determined the variation curves of $\mathrm{PM}_{10}$ in relation to each of meteorological parameters: temperature, 
intensity of solar radiation, and relative humidity, specific to each season. Also, the amount of $\mathrm{PM}_{10}$ variation was evidenced in relation to all three meteorological parameters specified above, expressed in the form of multiple linear regression equations. The correlation between measured data and those estimated based on identified regression functions is strong for winter and spring seasons and moderate for summer and autumn seasons.

The interpretation of values for correlation coefficients leads to the following conclusion: by knowing this variation functions, can be estimated the $\mathrm{PM}_{10}$ concentration in the atmosphere of Pitesti city at a future moment in time for which are known the prognoses on the values of the meteorological parameters specific to studied area.

The methodology proposed and validated through the case study in this paper represents an effective tool for determining the quantity of $\mathrm{PM}_{10}$ in the atmosphere, in the assumption that the amount of $\mathrm{PM}_{10}$ emitted remains constant in each hour of the average day associated with each season and in the assumption that are known the values of the meteorological parameters - temperature, intensity of solar radiation, and relative humidity.

Applying the same methodology can be analyzed the variations of other pollutants in relation to the meteorological parameters used in this case study. Also, for advanced analysis, which more faithfully reflects the actual phenomena of dispersion and transport of pollutants in the atmosphere, can be considered more meteorological parameters. In the future the authors intend to extend this type of analysis for a larger study area (metropolitan area, county area etc.).

\section{Acknowledgement}

This work was funded through the project PERFORM - Sustainable performance in doctoral and postdoctoral research, ID: POSDRU/159/1.5/S/138963, co-financed by the European Social Fund - Investing in People, within the Sectoral Operational Programme Human Resources Development 2007-2013.

\section{References}

Carnevale, C., Pisoni, E., \& Volta, M. (2008). A multi-objective problem to select optimal PM 10 control policies. In: Borrego, C. \& Miranda, A.I. Air Pollution Modeling and Its Application XIX. Springer Netherlands.

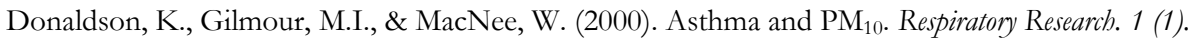

Dusa, A. (2007). Simple linear regression. University of Bucharest, Bucharest.

European Environment Agency. (2012). European Union emission inventory report 1990-2010 under the UNECE Convention on Long-range Transboundary Air Pollution (LRTAP). European Environment Agency Technical Report, Publications Office of the European Union.

Ministry of Environment and Forests, National Environmental Protection Agency. (2012). National Report on the State of the Environment 2011. Bucharest, Romania

N., Fernando, H., Runger, G., Hyde, P., Hedquist, B., Anderson, J., Bannister, W., \& Johnson, W. (2012). Relationship between particulate matter and childhood asthma - basis of a future warning system for central Phoenix. Atmospheric Chemistry and Physics, 12, 2479-2490. 
Parliament of Romania, (2011). Law no. 104 from June 15, 2011. Romanian legislation. ISBN 978-973-567-7664.

Ranzi, A., Gambini, M., Spattini, A., Galassi, C., Sesti, D., Bedeschi, M., Messori, A., Baroni A., Cavagni, G., \& Lauriola, P. (2004). Air pollution and respiratory status in asthmatic children: hints for a locally based preventive strategy. European Journal of Epidemiology, 19 (6), 567-576.

Song, P.X.K. (2007). Correlated data analysis: modeling, analytics and applications. New York, USA: Springer. 